\title{
DYNAMIC PCU VALUES AT SIGNALISED INTERSECTIONS IN INDIA FOR MIXED TRAFFIC
}

\author{
Sheela Alex ${ }^{1}$, Kuncheria P. Isaac ${ }^{2}$ \\ ${ }^{1}$ College of Engineering, Trivandrum, India \\ ${ }^{2}$ Kerala Technological University, Trivandrum, India
}

Received 10 February 2014; accepted 25 February 2015

\begin{abstract}
The traffic stream behaves differently in a mixed traffic condition as compared to that of a homogeneous condition. In a mixed traffic condition, as the traffic behaviour is always fluctuating based on the interaction caused by the surrounding elements, it is essential that the factors which affect the dynamic nature of the traffic characteristics should be considered for the proper design of the system. The paper highlights the methodology for developing the dynamic Passenger Car Unit (PCU) under various vehicular interactions for mixed traffic conditions prevalent in India. Experiments were carried out using the micro simulation model, TRAFFICSIM, which was developed for signalised intersections by the authors and reported elsewhere. The dynamic PCU values were obtained based on the analysis of the outputs of TRAFFICSIM, for varying approach width, traffic composition, stream speed and traffic volume. Modified area occupancy concept was used to develop Dynamic PCU values in a mixed traffic condition. In the modified area occupancy method, the area occupancy of the vehicle types for various traffic compositions is compared with area occupancy of the passenger cars in a car only traffic condition having the same stream speed. The study showed that the PCU values are highly sensitive to the given traffic conditions such as approach width, traffic composition, stream speed as well as flow ratio.
\end{abstract}

Keywords: dynamic PCU, simulation, TRAFFICSIM, area occupancy, mixed traffic.

\section{Introduction}

In a mixed traffic condition, the interaction of various classes of vehicles along a road creates many problems to the traffic engineers and planners due to the wide variation in their physical and operating characteristics. The non uniformity in the static and dynamic characteristics of the vehicles is normally taken into account by converting all vehicles in terms of a common unit known as Passenger Car Unit (PCU). Most of the existing analytical approaches based on the field data have the limitation of an underlying assumption of homogeneity, which is a long way from the high variations of driver vehicle characteristics in mixed traffic condition. Simulation models on the other hand, follow the dynamics of the traffic system, and give a continuous view of the state of the traffic system over time.

This paper focuses on the determination of the dynamic PCU values for different vehicle categories at signalised intersections under mixed traffic conditions by adopting a

${ }^{1}$ Corresponding author: sheelaalex@cet.ac.in 
modified concept of area occupancy. For this, the authors have developed a microscopic traffic simulation model, TRAFFICSIM, which was reported elsewhere. The paper explains the variation of dynamic PCU with traffic composition, width, stream speed and flow ratio. Using the obtained dynamic PCU values, a saturation flow model was developed, where the saturation flow is expressed in PCU/hr.

\section{Literature Review}

Researchers who have worked in the area of heterogeneous traffic condition defined PCU in different forms. PCU value depends on the factors such as vehicle characteristics, roadway characteristics, environmental conditions, climatic conditions, control conditions etc. In India, many researchers/ organisations have worked out the PCU values at urban as well as for rural roads and intersections. Indian Roads Congress Special Publications (IRC SP: 41) had recommended PCU values for two wheeler as 0.3 , three wheeler as 0.4 and bus/lorry as 2.8 for conversion of different types of vehicles into equivalent PCU.

Dynamic PCU model concept developed by Chandra and Sikdar (1993) considered the intersection clearing speed of each category of vehicles. Arasan and Jagadeesh (1995) estimated the PCU for different categories of vehicles using the multiple linear regression procedure, where the saturated green time was regressed against the number of each category of vehicles crossing the stop line, during the green time, assuming a linear relationship between the variables. PCU values obtained were for bus in the range of 2.11 to 2.83 , for two wheeler 0.30 to 0.38 and for three wheeler 0.58 to 0.64 . Vien et al. (2003) have developed a statistical approach of headway ratio method for finding the PCU values of different vehicles at signalised intersections with respect to Malaysian traffic conditions. Rahman et al. (2004) presented a procedure for estimating PCE of rickshaws and auto rickshaws at signalised intersections and suggested that the PCE values for rickshaws and autorickshaws varies from 0.75 to 1.0 and 0.35 to 1.0 respectively depending on the proportion of vehicles in mixed traffic flow. Patil et al. (2007) studied the influence of area type in the PCU values and estimated that the PCU for two wheeler ranges from 0.09 to 1.23 , three wheeler from 0.23 to 6.14 and that of bus from 1.02 to 3.78 .

Arasan and Krishnamurthy (2008) conducted a study on the effect of traffic volume and road width on PCU values of vehicles using microscopic simulation at mid block sections of urban roads. The results showed that the PCU value of a vehicle significantly changes with change in traffic volume. Arasan and Dhivya (2008) incorporated the concept of area occupancy and showed the appropriateness of the concept in heterogeneous traffic condition for urban roads. Arasan and Arkatkar (2010) used the simulation model, HETEROSIM, to derive the PCU values for different types of vehicles in urban roads. The results showed that the PCU value of a vehicle significantly changes with change in traffic volume and width of roadway. Radhakrishnan and Mathew (2011) in their study have proposed an optimisation technique for the computation of dynamic PCU values. PCU values obtained were 0.34 for two wheeler, 1.88 for three wheeler and 3.90 for heavy vehicles considering eight intersection approaches and 0.24 for two wheeler, 0.6 for three wheeler and 2.26 for heavy vehicles considering eleven intersection approaches. Arasan and Arkatkar (2011) quantified the 
vehicular interaction in terms of PCU for an intercity road in India. Joshi and Vagadia (2013), Praveen and Arasan (2013) have derived the vehicle equivalency factors for urban roads in India. It was found that under heterogeneous traffic conditions, for a given roadway and traffic composition, the PCU value of vehicles vary significantly with change in traffic volume. Hence it is desirable to consider PCU as a dynamic quantity instead of assigning fixed PCU values for the different vehicle categories of road traffic. Most of the research works, already done determined the PCU values of vehicles on midblock sections. Only a few literatures are there for determining the PCU values of vehicles at signalised intersection. Hence, it is obvious from research point of view that the need to establish a dynamic PCU model at signalised intersection by considering various factors during saturation and non saturation period, in a mixed traffic condition, is highly relevant.

\section{Objectives and Scope of the Work}

The objective of the research work presented in the paper is to determine the dynamic PCU values for varying traffic composition and geometric conditions, at signalised intersections in India. Sheela and Isaac (2014) recently developed a traffic simulation model, TRAFFICSIM, which was used to study the vehicular interactions, at micro level, over a wide range of traffic flow conditions at signalised intersections. The readers are advised to refer the paper titled 'Traffic Simulation Model and its application for estimating Saturation flow at Signalised intersections' published in the IJTTE journal, September 2014. The effect of traffic composition, width of the approach, stream speed as well as flow ratio on PCU values were also studied. Finally a check for the accuracy of the estimated PCU values were also analysed by developing a model for saturation flow in PCU/hr. The scope of this work was limited to four legged signalised intersections of carriageway widths varying from 3.5 to $10.5 \mathrm{~m}$ on level stretches.

\section{Methodology}

In a mixed traffic condition, the required space for the vehicular movement is reflected more by area of the vehicle than by length of the vehicle alone. Thus area occupancy of vehicle was used as the key parameter in the analysis, which incorporates the effect of all the vehicular interactions caused by the surrounding environment. To determine PCUs for signalised intersections in Indian conditions, a modified area occupancy concept is introduced in this study. In the modified area occupancy method, the area occupancy of different category vehicle at various traffic compositions is compared with that of the passenger cars in a car only traffic conditions having the same stream speed. The area occupancy is calculated using Eq. (1) as given by Arasan and Dhivya (2008):

Area occupancy $=\sum_{i=1}^{n} a_{i} t_{i} / A T$

where, ai is the area of the vehicle $i$ falling on the detection zone in $\mathrm{m} 2$, ti is the time during which the detection zone is occupied by vehicle $i$ in seconds, $A$ is the area of the whole of the road stretch (detection zone) in $\mathrm{m} 2$, $\mathrm{T}$ is the total observation period in seconds and $\mathrm{n}$ is the number of vehicles occupied the detection zone. Fig. 1 shows the concept of modified area occupancy. In the figure, the area of the detection zone is marked as LxW, where $L$ is the length of the detection zone and $\mathrm{W}$ is the width of the detection zone. 


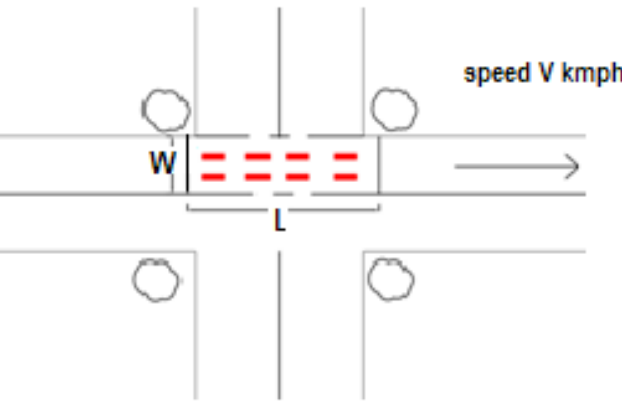

(a)

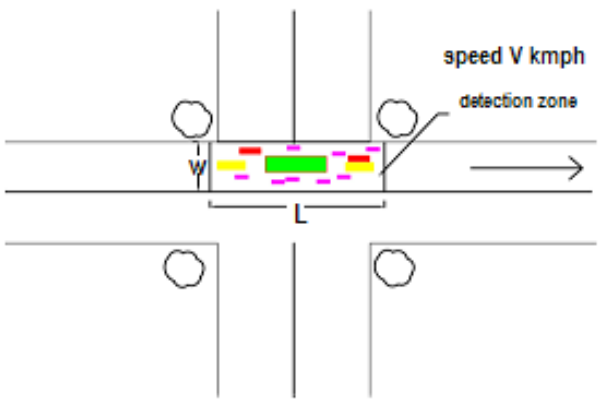

(b)

Fig. 1.

Modified Area Occupancy Concept

Fig. 1(a) shows the detection zone having $100 \%$ car only and Fig. 1(b) shows the equivalent detection zone having mixed traffic, both having the same stream speed of $\mathrm{V} \mathrm{kmph}$.
Thus the PCU value of any particular vehicle type is obtained as the ratio of the equivalent area occupancy of that vehicle category to the equivalent area occupancy of car in a $100 \%$ car only traffic condition as given in Eq. (2).

$$
\text { PCU of a vehicle type }=\frac{\text { Equivalent area occupancy of that vehicle type }}{\text { Equivalent area occupancy of car in a } 100 \% \text { car only condition }}
$$

The equivalent area occupancy of a vehicle is analysed by dividing the total area occupancy of each vehicle category by the number of vehicles in that category. The total observation time period per cycle is taken as the time period during which the first vehicle entering the detection zone to the time at which the last vehicle leaving the zone. Occupancy time of vehicles ( $\mathrm{ti}$ ) when clearing the intersection is obtained as the time taken by a vehicle entering the clearing section of an intersection to the time it clears the intersection. Also in the case of mixed traffic, since the vehicles occupy the entire space of the road width, the whole width of the carriageway is considered for the computation of area occupancy. Hence the area of the detection zone is incorporated in the calculation of area occupancy.

\subsection{Dynamic PCU Values in a Mixed Traffic Stream}

In order to study the variation of PCU with the proportion of different classes of vehicles under mixed traffic conditions, the validated TRAFFICSIM model was applied to study the traffic flow characteristics by experimenting the model for varying traffic composition and approach width. To estimate the PCU values of various types of vehicles in a mixed traffic stream, simulation model was run on both cars only traffic and for mixed traffic condition by varying the traffic composition of each vehicle type between 0 to $50 \%$ for different approach widths such as $3.5,5.5,7,9$ and $10.5 \mathrm{~m}$ and for different traffic volumes. The traffic stream speed varied correspondingly. As 
per IRC, the maximum cycle time suggested is $120 \mathrm{~s}$. In order to study the effect of traffic composition on saturation flow, cycle time of $120 \mathrm{~s}$ was adopted with an effective green time of $56 \mathrm{~s}$ for all the simulation runs. The movement of vehicles during green phase at saturated condition as well as non saturated condition, i.e. at capacity or at values lower than the capacity, was analysed. The observed speed from the field data showed that the stream speeds during saturation flow at the detection zone is less than $30 \mathrm{kmph}$. Based on the speed data obtained from the simulation output, each cycle was divided into two phases, saturated as well as non saturated period. Stream speed of the mixed traffic stream must be same as that of car only traffic condition. Using the data obtained from the simulation model, equivalent area occupancy of corresponding vehicle types during saturated as well as non saturated traffic conditions were determined, and the PCU values were calculated using Eq. (2) as mentioned in the methodology. PCU models were then developed at saturation as well as at non saturation traffic conditions, with PCU of the vehicle category as dependent variable and the proportions of two wheeler, three wheeler, car, bus, stream speed and width as independent variables along with a constant term as shown in Table 1 and 2 respectively.

\section{Table 1}

Dynamic PCU Models in a Mixed Traffic during Saturation Period

\begin{tabular}{|l|l|l|l|}
\hline PCU Model & $\mathbf{N}$ & S.E & $\mathbf{R}^{2}$ \\
\hline $\begin{array}{l}\text { pcutwowheeler }=0.525-0.181 \text { two_wheeler }-0.409 \text { three_wheeler }-0.48 \\
\text { car - } 0.57 \text { bus }-0.003 \text { speed }+0.011 \text { width }\end{array}$ & 135 & 0.035 & 0.60 \\
\hline $\begin{array}{l}\text { pcuthreewheeler }=2.251-1.839 \text { two_wheeler }-1.69 \text { three_wheeler }-2.18 \\
\text { car }-2.09 \text { bus - } 0.003 \text { speed }+0.03 \text { width }\end{array}$ & 135 & 0.09 & 0.52 \\
\hline $\begin{array}{l}\text { pcucar }=3.003-2.61 \text { two_wheeler }-2.48 \text { three_wheeler } \\
-2.59 \text { car }-2.45 \text { bus }+0.006 \text { speed }+0.065 \text { width }\end{array}$ & 135 & 0.13 & 0.52 \\
\hline $\begin{array}{l}\text { pcubus }=-2.313+1.995 \text { two_wheeler }+1.81 \text { three_wheeler } \\
+2.19 \text { car }+5.32 \text { bus }+0.083 \text { speed }+0.185 \text { width }\end{array}$ & 130 & 0.65 & 0.59 \\
\hline
\end{tabular}

Table 2

Dynamic PCU Model in a Mixed Traffic during Non Saturation Period

\begin{tabular}{|l|l|l|l|}
\hline PCU Model & $\mathbf{N}$ & S.E & $\mathbf{R}^{2}$ \\
\hline $\begin{array}{l}\text { pcutwowheeler }=0.331+0.194 \text { two_wheeler }-0.032 \text { three_wheeler - } \\
0.094 \text { car }-0.23 \text { bus }-0.008 \text { speed }+0.016 \text { width }\end{array}$ & 128 & 0.04 & 0.69 \\
\hline $\begin{array}{l}\text { pcuthreewheeler }=-2.142+3.175 \text { two_wheeler }+3.26 \text { three_wheeler }+ \\
2.82 \text { car }+2.77 \text { bus }-0.018 \text { speed + 0.042 width }\end{array}$ & 127 & 0.09 & 0.57 \\
\hline $\begin{array}{l}\text { pcucar }=-1.45+3.04 \text { two_wheeler }+3.03 \text { three_wheeler - } \\
3.28 \text { car }+3.17 \text { bus }-0.03 \text { speed }+0.06 \text { width }\end{array}$ & 127 & 0.09 & 0.54 \\
\hline $\begin{array}{l}\text { pcubus }=15.295-8.18 \text { two_wheeler }-8.28 \text { three_wheeler - } \\
8.25 \text { car }-2.575 \text { bus - } 0.145 \text { speed }+0.192 \text { width }\end{array}$ & 121 & 1.1 & 0.53 \\
\hline
\end{tabular}


Where, two_wheeler is the proportion of two wheeler, car is the proportion of car in a heterogeneous traffic, three_wheeler is the proportion of three wheeler, bus is the proportion of bus, speed is the stream speed in $\mathrm{kmph}$ and width is the width of the approach in $\mathrm{m}, \mathrm{N}$ and S.E are the sample size and standard error of the regression model.

From the developed PCU models, it is observed that the dynamic PCU values for all categories of vehicles have got a negative correlation with the speed and a positive correlation with the width, during saturated condition. This indicates that the PCU value decreases, as the stream speed increases. When the speed of a particular vehicle increases, the occupancy time of that vehicle type in the detection zone decreases, and hence the PCU value decreases. This has got an exception in the case of PCU of car and that of bus, in saturated condition. During saturated condition, when the speed of the heavy vehicles like bus and car increases, which means the speed differential between the vehicles increases causing more interaction among vehicle types, hence the PCU value increases, this might be the reason for that exception. From all the developed models, it shows that as the width increases, the PCU value also increases for all categories of vehicles. This behaviour is due to the freedom of movement experienced by the individual vehicles at wider approach, keeping the flow rate same. This results in more speed differential between vehicles, causing more PCU value.

\section{Variation of Dynamic PCU with Traffic Parameters}

i) Variation of dynamic PCU with approach width

To analyse the effect of approach width on PCU values during saturation period, the dynamic PCU models given in Table 1 were used. In urban cities, the normal traffic composition was of $40 \%$ two wheeler, $20 \%$ three wheeler, $30 \%$ car and $10 \%$ bus, which was chosen for the analysis. Fig. 2 shows the variation of PCU values of two wheeler, three wheeler, car and bus with width, during saturation for the percentage composition of $40 \%$ two wheelers, $20 \%$ three wheelers, $30 \%$ cars and $10 \%$ buses and a stream speed of $25 \mathrm{kmph}$.

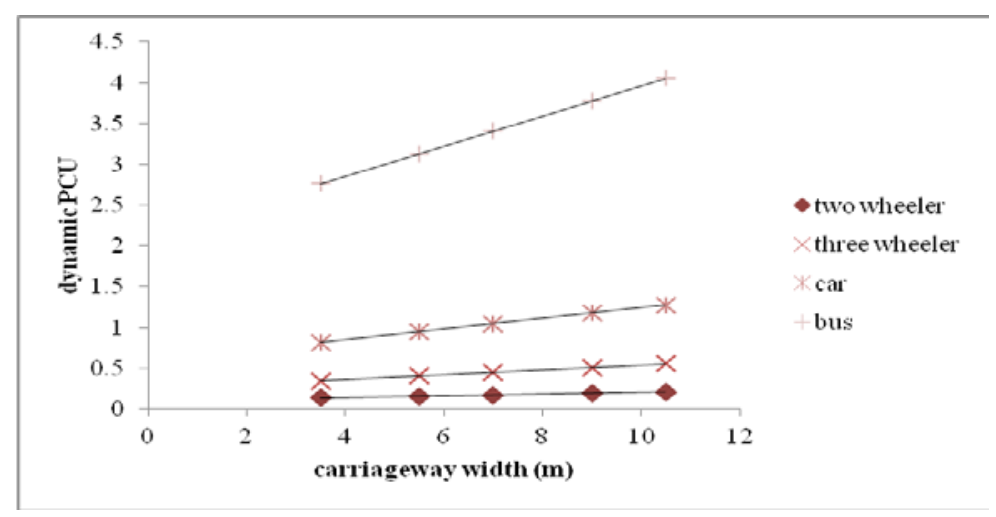

Fig. 2.

Variation of PCU with Width for a Traffic Composition of 40-20-30-10 
From Fig. 2, it is seen that as width increases, the PCU value increases, for a given proportion of two wheeler, three wheeler, car and bus. This may be due to the freedom of vehicles to choose the speed, as the width increases. This may cause high speed differential among vehicles causing mutual interactions among vehicles. It is observed that the PCU value for bus varies slightly more compared to two wheeler, three wheeler and car with respect to width. The reason might be larger is the vehicle, the lesser is its maneuverability, greater its hindrance to other vehicles and hence greater is its PCU. ii) Variation of dynamic PCU with stream speed

To study the effect of stream speed on PCU values, the developed PCU models were made use of.

For a particular proportion of two wheeler, three wheeler, car and bus and also for a particular carriageway width, the variation in the obtained PCU values was studied. Figs. 3-6 show the variation of PCU with stream speed for varying carriageway widths. For the analysis, the percentage composition chosen were $40 \%$ two wheelers, $20 \%$ three wheelers, $30 \%$ cars and $10 \%$ buses.

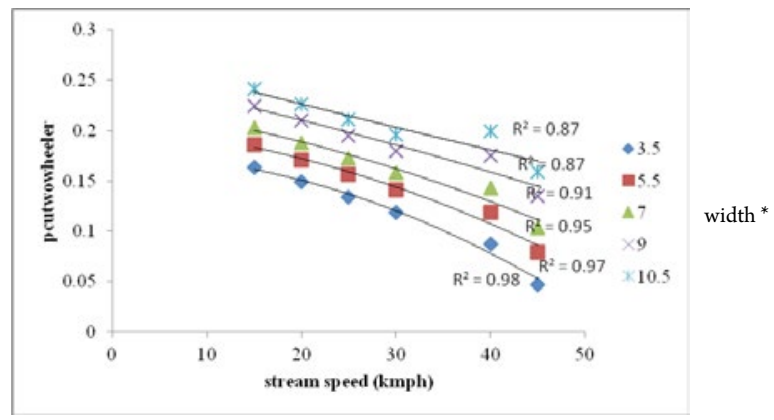

( ${ }^{*}$ width represents carriageway width, $m$ )

Fig. 3.

Variation of PCU of Two Wheeler with Stream Speed for Varying Carriageway Width

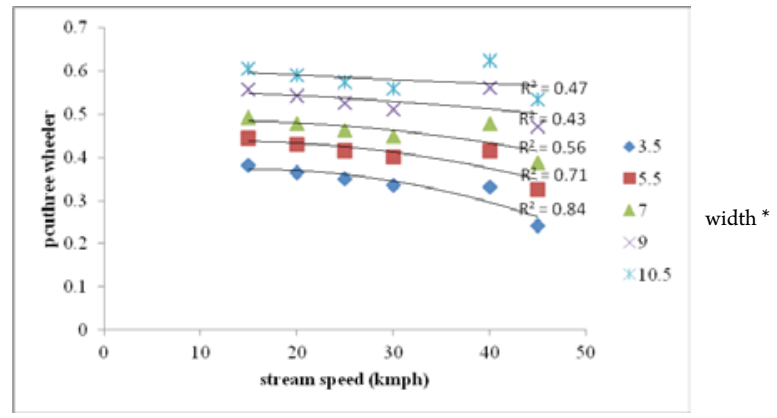

( ${ }^{*}$ width represents carriageway width, $m$ )

Fig. 4.

Variation of PCU of Three Wheeler with Stream Speed for Varying Carriageway Width 


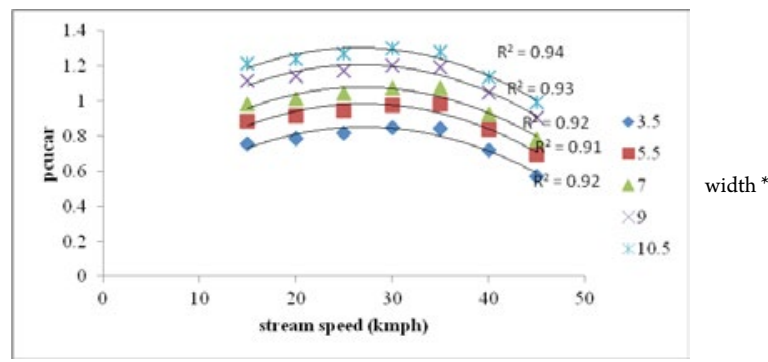

( ${ }^{*}$ width represents carriageway width, $m$ )

Fig. 5.

Variation of PCU of Car with Stream Speed for Varying Carriageway Width

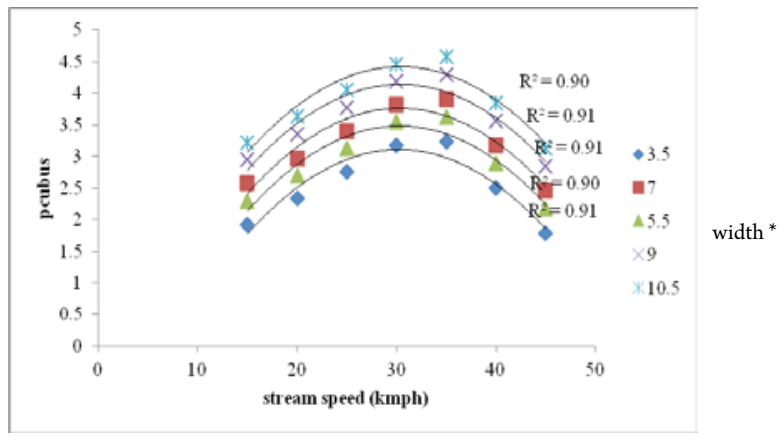

( ${ }^{*}$ width represents carriageway width, $m$ )

Fig. 6.

Variation of PCU of Bus with Stream Speed for Varying Carriageway Width

It is observed that PCU values of two wheeler and three wheeler decreases with increase in stream speed, whereas the PCU values of car and that of bus increases, during saturation stage, as the vehicles are moved with a speed almost equivalent to that of stream speed. Though the stream speed increases, the smaller vehicles like two wheeler and three wheeler utilised the narrow gaps and due to this the heavier vehicles have less freedom to move freely, which will cause a high speed differential between the vehicles. This will cause higher PCU values for cars and buses, when the stream speed increases. To study the effect of stream speed on PCU during non saturated stage, the developed PCU models given in Table 2 were utilised. Same percentage composition of traffic as in the case of saturation period was taken for the analysis. From field observations, it was observed that during non saturation period, the stream speed of the traffic stream was more than $30 \mathrm{kmph}$. It is observed that PCU values of two wheeler, three wheeler, car and bus decreases with increase in stream speed. During non saturation period, when the traffic volume decreases, naturally the speed of the entire vehicle category increases, causing fewer interactions. This will cause lesser PCU values for the vehicles, when the stream speed increases. 
iii) Variation of dynamic PCU with traffic composition

The variation of PCU with proportion of vehicles in a mixed traffic condition for a width of $7 \mathrm{~m}$, during saturation, is given in Fig. 7. Figure shows that when the proportion of vehicles varies from 0 to 0.5 ( 0 to $50 \%$ ),
PCU of two wheeler increases from 0.04 to 0.24 , three wheeler varies from 0.37 to 0.55 , car varies from 1.03 to 0.98 and that of bus 2.20 to 3.90. PCU of a particular vehicle category not only depends on its own proportion, but also on the composition of other categories of vehicles.

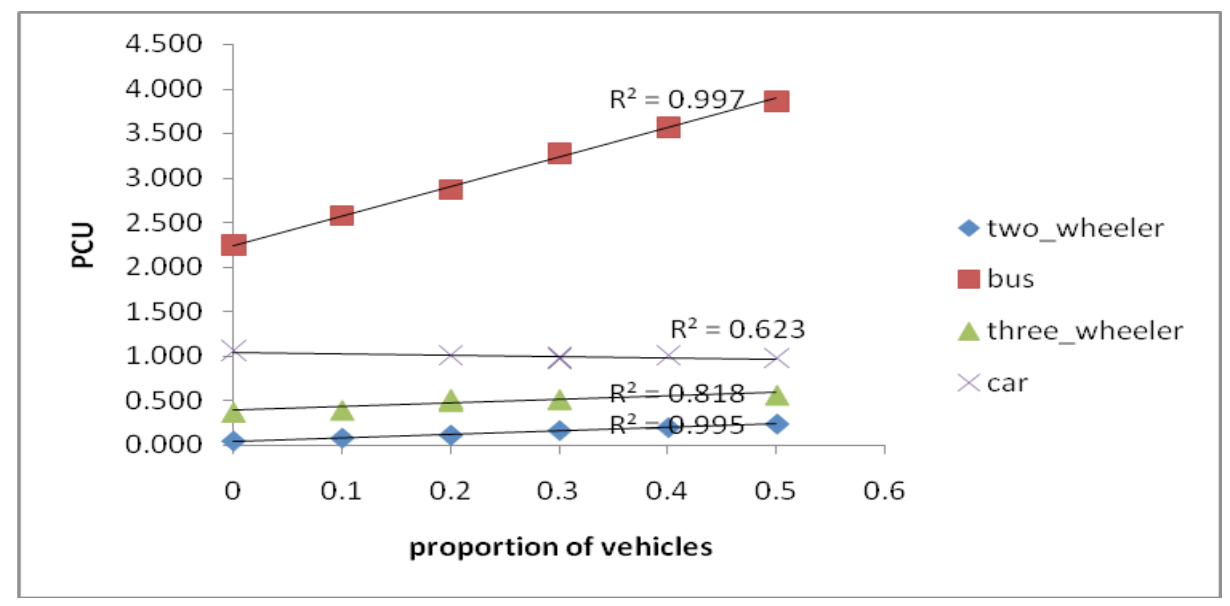

Fig. 7.

Variation of PCU with Proportion of Vehicles during Saturation

In a mixed traffic condition, when the proportion of smaller vehicles increases, maximum road width utilisation takes place, as the vehicles occupy every minute space in between the heavy vehicles.

During saturation, as proportion of vehicles increases, more distraction of movement to other vehicles occurs, hence PCU of different vehicle type increases. Again as the proportion of a particular vehicle category increases, the proportion of time that particular vehicle category occupies the detection zone increases, which increases the area occupancy, causing higher PCU values. iv) Variation of dynamic PCU with flow ratio

In order to study the effect of flow ratio, i.e. the ratio of flow $(q)$ to saturation flow $(S)$ during each cycle was calculated for a particular width. Saturation flow $S$ in $\mathrm{pc} / \mathrm{hr}$ was obtained using the model shown in Eq. (3) developed by the authors mentioned in the paper titled 'Traffic Simulation Model and its application for estimating the Saturation flow at Signalised intersections' published in the IJTTE journal, September 2014.

$\mathrm{S}=522 \mathrm{w}$, where $w$ is the approach width in $\mathrm{m}$ 
Corresponding dynamic PCU values were calculated based on the proportion of vehicle categories. Flow in PCU/hr was obtained by multiplying the number of vehicles in each category by the corresponding dynamic PCU values. In order to study the effect of PCU on flow ratio $(q / s)$, a non linear model of second degree which shows high statistical significance was developed. In order to check the significance of width, two widths were considered. Figs. 8 and 9 show the variation of PCU with flow ratio for a width of $9 \mathrm{~m}$ and $7 \mathrm{~m}$ respectively.

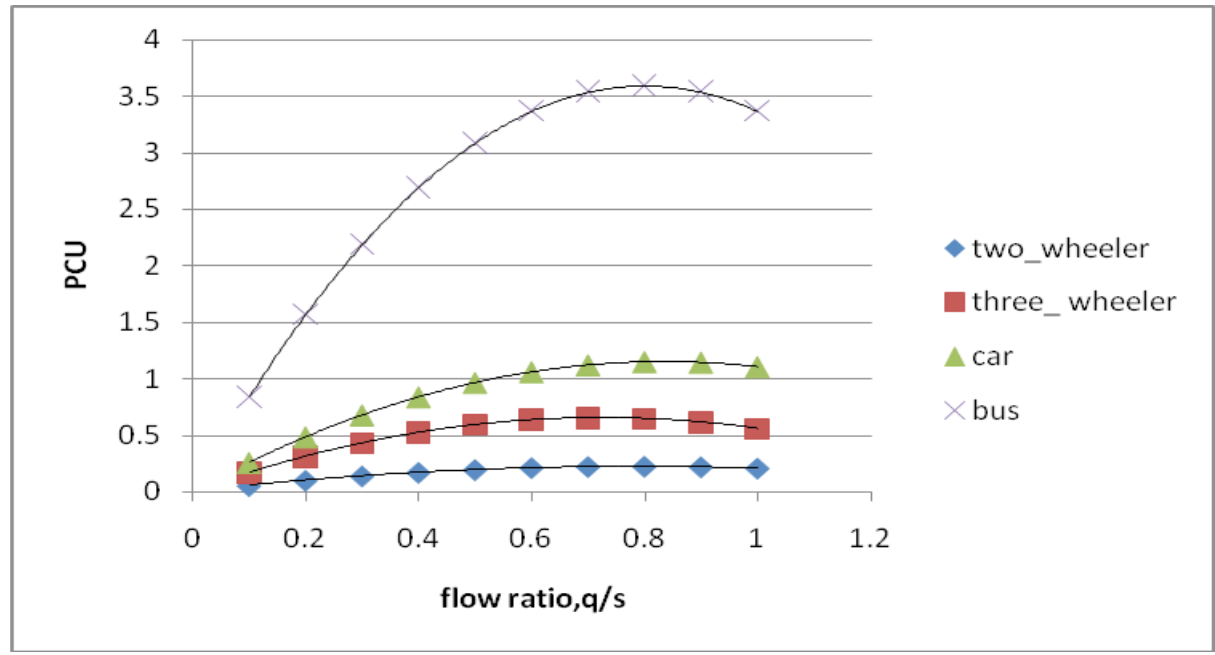

Fig. 8.

Variation of PCU with Flow Ratio for a Width of $9 \mathrm{~m}$

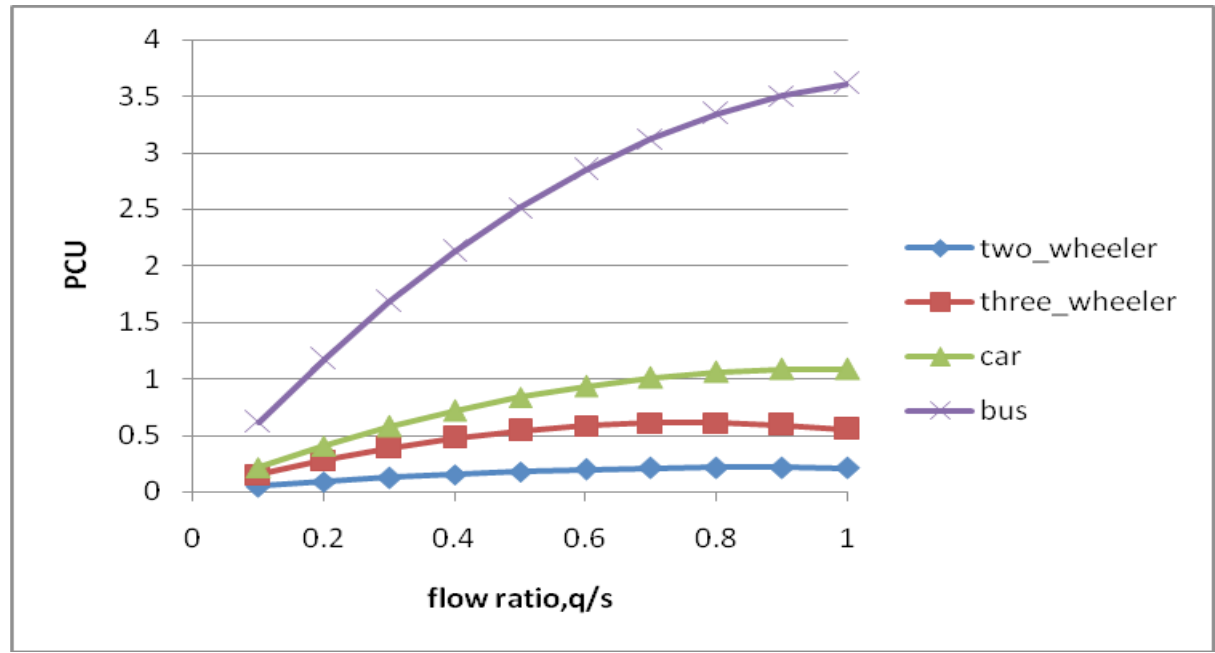

Fig. 9.

Variation of PCU with Flow Ratio for a Width of $7 \mathrm{~m}$ 
For a width of $7 \mathrm{~m}$, the PCU of two wheeler, three wheeler slightly decreases when the flow ratio reaches 0.9 , and for a width of $9 \mathrm{~m}$, the PCU of two wheeler, three wheeler, car and bus shows a trend of decreasing when flow ratio reaches 0.8 . The reason may be as flow reaches full saturation, the speed differential of the vehicles of the entire stream is less.
This indicates that as width increases, the PCU value starts decreasing at lower flow ratio as the interaction caused by the vehicles decreases. Table 3 shows the PCU values of vehicles for varying flow ratio for a width of $7 \mathrm{~m}$ which was obtained from the developed second degree relationship between flow ratio and the PCU of different vehicle categories.

Table 3

Variation of PCU with Flow Ratio

\begin{tabular}{|l|l|l|l|l|l|l|l|l|l|l|}
\hline \multirow{2}{*}{ Vehicle type } & \multicolumn{2}{l}{ Flow ratio } \\
\cline { 2 - 13 } & $\mathbf{0 . 1}$ & $\mathbf{0 . 2}$ & $\mathbf{0 . 3}$ & $\mathbf{0 . 4}$ & $\mathbf{0 . 5}$ & $\mathbf{0 . 6}$ & $\mathbf{0 . 7}$ & $\mathbf{0 . 8}$ & $\mathbf{0 . 9}$ & $\mathbf{1}$ \\
\hline Two wheeler & 0.05 & 0.09 & 0.13 & 0.16 & 0.18 & 0.19 & 0.21 & 0.21 & 0.21 & 0.21 \\
\hline Three wheeler & 0.15 & 0.28 & 0.39 & 0.48 & 0.54 & 0.59 & 0.61 & 0.61 & 0.59 & 0.55 \\
\hline Car & 0.21 & 0.41 & 0.57 & 0.72 & 0.83 & 0.93 & 1.01 & 1.06 & 1.08 & 1.08 \\
\hline Bus & 0.61 & 1.18 & 1.68 & 2.12 & 2.51 & 2.85 & 3.12 & 3.34 & 3.5 & 3.61 \\
\hline
\end{tabular}

\section{Application of Dynamic PCU Values}

In order to develop a saturation flow model in $\mathrm{PCU} / \mathrm{hr}$, linear regression analysis was done to obtain a relationship between the percentage composition of vehicle categories, width of the approach and the saturation flow in PCU/hr. Same set of data which were used for the development of saturation flow in veh/hr was taken for the analysis. For each composition and for each width, corresponding PCU values were estimated from the developed PCU models. These PCU values were multiplied with the corresponding volume of each vehicle category to obtain the saturation flow in PCU/hr.
The model obtained is as shown in Eq. (4).

$\mathrm{Sp}=6.23$ ptwo_wheeler +12.67 pthree wheeler +4.81 pcar +19.52 pbus +389.08 width

where, $\mathrm{Sp}$ is the saturation flow (PCU/hr), ptwo_wheeler, pthree_wheeler, pcar and pbus are percentage of two wheelers, three wheelers, cars and buses respectively and width is the approach width (m). Table 4 gives the saturation flow model regression statistics, which gives a high $\mathrm{R} 2$ value and the calculated $t$-values are higher than the critical values, which shows that the model is statistically significant.

Table 4

Saturation Model Regression Statistics

\begin{tabular}{|l|l|l|l|l|}
\hline Variable & Coefficients & t value & $\mathrm{N}$ & $\mathrm{R}^{2}$ \\
\hline ptwo_wheeler & 6.225 & 2.719 & & \\
\cline { 1 - 2 } pthree_wheeler & 12.677 & 4.710 & \multirow{2}{*}{68} & \\
\cline { 1 - 3 } pcar & 4.813 & 1.863 & & \\
\cline { 1 - 3 } pbus & 19.520 & 3.699 & & \\
\hline width & 389.084 & 15.886 & & \\
\hline
\end{tabular}


In order to check the validity of the models, assuming a $100 \%$ car condition, the saturation flow value estimated using model in Eq. (4) is $1905 \mathrm{PCU} / \mathrm{hr} /$ lane width of $3.66 \mathrm{~m}$ as against $1900 \mathrm{PCU} / \mathrm{hr} /$ lane as per HCM 2010. On comparing this value, with the value obtained in a homogeneous traffic condition, was estimated as $1911 \mathrm{PCU} / \mathrm{hr}$ as the base saturation flow in an ideal condition as per Eq. (3). Hence the model developed is considered to be highly reliable for the prediction of saturation flow in PCU/hr.

\section{Summary and Conclusion}

The paper presented the methodology for the determination of Dynamic PCU values at signalised intersections using the outputs obtained from the micro simulation model, TRAFFICSIM. The experimentation of the simulation model has been carried out for wide ranges of traffic composition and approach widths and the outputs were analysed. A new concept of modified area occupancy method was used for the determination of dynamic PCU values, which is different from the methods adopted by the previous researchers. This paper clearly explained the significance of PCU values, and has been proved that the PCU values are highly sensitive to the given traffic and geometric condition such as approach width, stream speed, traffic composition as well as traffic volume. The conclusions arrived are:

1. In a mixed traffic condition, when the proportion of vehicles varies from 0 to $50 \%, \mathrm{PCU}$ of two wheeler increases from 0.05 to 0.24 , three wheeler varies from 0.37 to 0.56 , car varies from 1.03 to 0.98 and that of bus 2.20 to 3.90 .
2. The dynamic PCU value for all categories of vehicles has got a negative correlation with the stream speed except in the case of PCU of car and that of bus, in saturated condition. It was also observed that PCU values of two wheeler, three wheeler, car and bus decreases with increase in stream speed, during non saturation stage.

3. For a flow ratio from 0.1 to 1 , the PCU of two wheeler, three wheeler, car and bus varies in the range from 0.05 to 0.21 , 0.15 to $0.55,0.21$ to 1.08 and 0.61 to 3.59 respectively.

4. A highly reliable Saturation flow model was also developed using the dynamic PCU values.

\section{References}

Arasan, V.T.; Arkatkar, S.S. 2010. Microsimulation Study of Effect of Volume and Road Width on PCU of Vehicles Under Heterogeneous Traffic, Journal of Transportation Engineering, ASCE. DOI: http://dx.doi.org/10.1061/ (ASCE)TE.1943-5436.0000176, 136(12): 1110-1119.

Arasan, V.T.; Jagadeesh, K. 1995. Effect of Heterogeneity of Traffic on Delay at Signalized Intersections, Journal of Transportation Engineering. DOI: http://dx.doi. org/10.1061/(ASCE)0733-947X(1995)121:5(397), 121(5): 397-404.

Arasan, V.T.; Krishnamurthy, K. 2008. Study of the Effect of Traffic Volume and Road Width on PCU Values of Vehicles Using Microscopic Simulation, Journal of the Indian Roads Congress. DOI: http://dx.doi.org/10.1061/ (ASCE)TE.1943-5436.0000176, 69(2): 133-149.

Arasan, V.T; Arkatkar, S.S. 2011. Microsimulation Study of Vehicular Interactions in Heterogeneous Traffic Flow on Intercity Roads, European Transport, 48: 60-86. 
Arasan,V.T.; Dhivya, G. 2008. Measuring Heterogeneous Traffic Density, World Academy of Science, Engineering and Technology, 2: 10-22.

Chandra, S.; Sikdar, P.K. 1993. Dynamic PCU for Intersection Capacity Estimation, Indian Highways, 23(4): 5-11.

Highway Capacity Manual. 2010. Transportation Research Board, National Research Council, Washington, D.C.

Indian Roads Congress. 1994. Guidelines for the Design of At-Grade Intersections in Rural and Urban Areas-Special Publication 41. IRC, New Delhi, India.

Joshi, G.; Vagadia, D. 2013. Dynamic vehicle equivalent factors for characterization of mixed traffic for multilane metropolitan arterials in India, Journal of Indian Roads Congress, 74(2): 205-219.

Patil, G.R.; Krishna Rao, K.V.; Xu, N. 2007. Saturation flow Estimation at signalized intersections in Developing countries, $86^{\text {th }}$ Transportation Research Board Annual Meeting,Washington, D.C, 07-1570.

Praveen, P.S.; Arasan, V.T. 2013. Influence of traffic mix on PCU value of vehicles under heterogeneous traffic conditions, International journal for Traffic and Transport Engineering. DOI: http://dx.doi.org/10.7708/ ijtte.2013.3(3).07, 3(3): 302-330.
Radhakrishnan, P.; Mathew, V.T. 2011. Passenger car units and saturation flow models for highly heterogeneous traffic at urban signalised intersections, Transportmetrica. DOI: http://dx.doi. org/10.1080/18128600903351001, 7(2): 141-162.

Rahman, M.M.; Okura, I.; Nakamura, F. 2004. Effects of Rickshaws and Auto-Rickshaws on the Capacity of Urban Signalized Intersections, IATSS Research. DOI: http://dx.doi.org/10.1016/S0386-1112(14)60089-3, 28(1): 26-33.

Sheela, A.; Isaac, K.P. 2014. Traffic simulation model and its application for estimating saturation flow at signalised intersection, International Journal of Traffic and Transport Engineering. DOI: http://dx.doi.org/10.7708/ ijtte.2014.4(3).06, 4(3): 320-338.

Vien, L.L.; Ibrahim, W.H.W.; Sadullah, A.F.M. 2003. Determination of passenger car equivalents using the headway ratio method at signalsed intersection, International Journal of Engineering Science and Technology, 3(2): 109-214. 